\title{
Crescimento e produção de raízes comercializáveis de mandioquinha- salsa em resposta à aplicação de nutrientes
}

\author{
Adriano Portz; Carla Andréia C. Martins; Eduardo Lima \\ UFRRJ, Depto. Solos, BR 465, km 7, 28851-000 Seropédica-RJ; E-mail:portza@ufrrj.br
}

\section{RESUMO}

A produção de mandioquinha-salsa (Arracacia xanthorrhiza Bancroft) vem aumentando marcadamente em algumas regiões do Brasil, com uma crescente demanda nos grandes centros consumidores. O desenvolvimento e produção desta espécie no estado do Rio de Janeiro foi avaliado, em condições de campo, em um experimento com três níveis de nitrogênio, fósforo e potássio em esquema fatorial, num delineamento de blocos ao acaso com quatro repetições. Foram realizadas amostragens, da planta inteira, da parte aérea, do propágulo e da raiz, em quatro épocas ao longo do ciclo da cultura. O maior acúmulo da massa seca na parte aérea ocorreu aos 180 dias e, em relação ao propágulo e às raízes, aos 300 dias depois do transplante. Não foram observadas respostas significativas na produtividade de raízes comercializáveis às doses aplicadas de fósforo e potássio e a maior produtividade foi alcançada com a dose de 60 $\mathrm{kg} \cdot \mathrm{ha}^{-1}$ de N.

Palavras-chave: Arracacia xanthorrhiza Bancroft, nutrição, fertilizante, nitrogênio, fósforo, potássio.

\begin{abstract}
Production of arracacha (Arracacia xanthorrhiza Bancroft) in increasing levels of nutrients

Arracacha production has been markedly increasing in some regions of Brazil, with a indreasing demand in the most important consuming centers. A field experiment was conducted with the objective of evaluating the development of this species in the State of Rio de Janeiro. Three levels of N, P and K were tested in completely randomized blocks design with four repetitions in a factorial scheme. Shoot, corm and root samples were collected four times along the plant cycle. The highest shoot dry weight accumulation was recorded at 180 days, for corm and roots at 300 days after planting. No Significant effects of phosphorus and potassium levels were observed and the highest production was reached with the level of $60 \mathrm{~kg} \cdot \mathrm{ha}^{-1}$ of $\mathrm{N}$.
\end{abstract}

Keywords: Arracacia xanthorrhiza Bancroft, plant nutrition, fertilizing, nitrogen, phosphorus, potassium.

\section{(Aceito para publicação em 25 de abril de 2002 e aceito em 18 de junho de 2003)}

$\mathrm{P}$ ara alcançar maior produtividade na cultura de mandioquinha-salsa é necessário avaliar o comportamento em diversos ambientes e regiões de produção. Apesar da cultura ter sido introduzida no País há um século na região serrana do Estado do Rio de Janeiro, não existem referências ou relatos de experimentos conduzidos na região. $\mathrm{O}$ clima de altitude $\mathrm{e}$ de temperaturas amenas favorece a produção desta hortaliça, de origem andina, em Nova Friburgo-RJ, que é o principal município produtor no Rio de Janeiro.

O consumo de "batata baroa", como é mais conhecida no Estado, vem despertando interesse, mas a produção está estagnada em pequenas propriedades (com menos de $1 \mathrm{ha}$ ) e com produtividade abaixo da média nacional $\left(9,2\right.$ t.ha $\left.{ }^{-1}\right)$ (Reghin et al., 2000). Além de não utilizar as técnicas mais recentes de propagação como o pré-enraizamento de mudas, os produtores necessitam de dados técnicos sobre a nutrição e fertilização da cultura na região.

Em experimento realizado em Piedade-SP, em solo do tipo massapê, Silva et al. (1966) observaram efeito altamente significativo e linear do fósfo- ro e efeito quadrático e negativo do potássio. Para nitrogênio, o efeito foi linear e negativo, contudo os autores atribuíram que as baixas produtividades foram devido à seca no período da condução do experimento. Segundo Silva \& Santos (1998), a falta de irrigação é o fator que mais tem contribuído para as baixas produtividades nas lavouras. Câmara et al. (1985), estudando a época de plantio e amassamento de pecíolos na mandioquinha-salsa, verificaram que tratamentos que promovam aumento na produção de raízes, também promovem acréscimos na produção de coroas e da parte aérea, considerando que houve correlação linear e positiva entre produção de raízes comerciais e produção de coroas $(r=0,77 ; p=0,01)$ e entre produção de raízes comerciais e peso da parte aérea $(r=0,46 ; p=0,01)$. Num experimento realizado em condições de campo, em Latossolo Vermelho amarelo distrófico (LVd), argiloso, Mesquita Filho et al. (1996) observaram que não houve resposta à adubação nitrogenada na produção de raízes comercializáveis e verificaram efeito quadrático significativo para o fósforo, quando utilizaram quatro níveis de uréia e quatro níveis de superfosfato triplo. Del Valle Junior et al. (1995), trabalhando com onze combinações de nutrientes com N, P, K e $\mathrm{Mg}$, em solo denominado Ultissol, observaram que a produção mais econômica foi obtida com a dose de $135 \mathrm{~kg} \cdot \mathrm{ha}^{-1}$ de $\mathrm{N}$, quando se mantinham os demais nutrientes em níveis fixos. Tratamentos com diferentes níveis de $\mathrm{P}$ e níveis fixos para os outros nutrientes não diferiram significativamente. A mesma falta de resposta foi observada para $\mathrm{K} \mathrm{e} \mathrm{Mg}$.

Vieira (1995), trabalhando em solo sob cerrado, observou que houve um aumento crescente na produtividade de raízes comerciais à medida que aumentaram as doses na combinação de fósforo e resíduo orgânico. A utilização de resíduos orgânicos é recomendada pela melhoria nas condições químicas e físicas dos solos além de promover o incremento da atividade biológica, contribuindo para o aumento da disponibilidade de vários nutrientes, entre eles o fósforo e o nitrogênio.

Com o objetivo de avaliar o desenvolvimento e as possibilidades de aumentar a produtividade da mandioquinha-salsa no Estado do Rio de Janeiro, aplicaram-se doses crescentes de N, P e K determinan- 


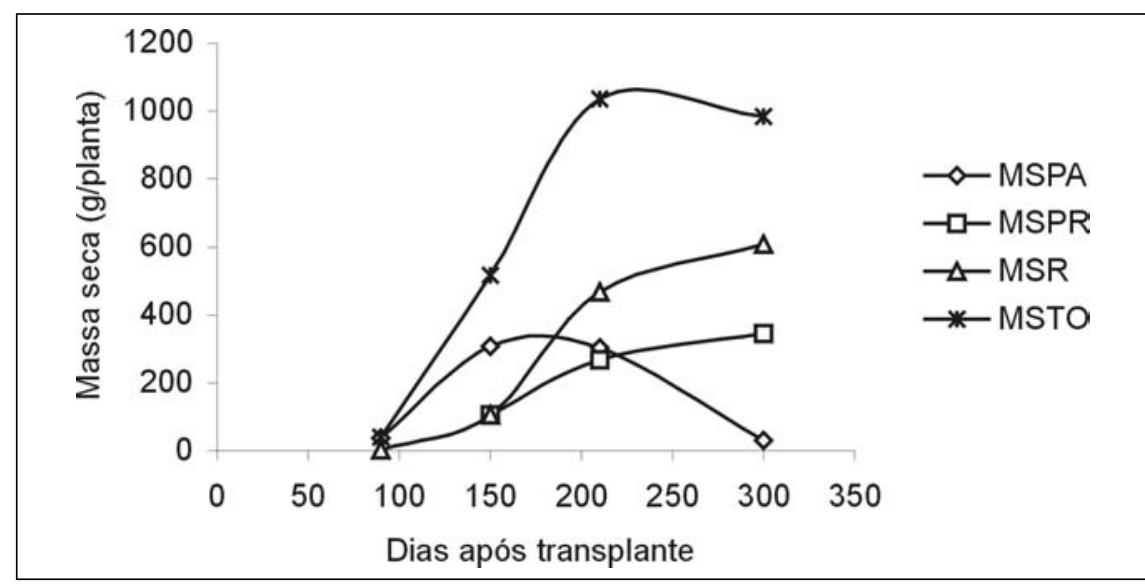

Figura 1. Acúmulo de massa seca da planta total (MSTO), massa seca da parte aérea (MSPA), massa seca de propágulo (MSPR) e massa seca de raiz (MSR) de todos os tratamentos nas quatro épocas de coleta da cultura de mandioquinha-salsa. Nova Friburgo, UFRRJ, 2000.

do-se a produção de raízes comercializáveis aos 300 dias do plantio das mudas.

\section{MATERIAL E MÉTODOS}

O experimento foi instalado em Friburgo, com altitude aproximada de $1.000 \mathrm{~m}$, precipitação pluviométrica média de $1.200 \mathrm{~mm}$ anuais e temperatura média anual de $20^{\circ} \mathrm{C}$. O solo classificado como Nitossolo, situa-se em meia encosta suave com $12 \%$ de declividade e na camada de 0-20 cm de profundidade, antes do início da instalação do experimento, possuía as seguintes características químicas: $\mathrm{pH}$ em água $(1: 2,5)=6,0 ; \mathrm{Al}^{+3}$ $=0,3$ cmolc. $\mathrm{kg}^{-1} ; \mathrm{H}+\mathrm{Al}=18,3$ cmolc $\cdot \mathrm{kg}^{-1}$; $\mathrm{Mg}^{+2}=0,9$ cmolc. $\mathrm{kg}^{-1} ; \mathrm{Ca}^{+2}=1,8$ cmolc.kg- $\mathrm{kg}^{-1} \mathrm{Na}^{+}=0,08$ cmolc.kg- ${ }^{-1} ; \mathrm{P}=11$ mg.kg-3 $; \mathrm{K}=148$ mg.kg ${ }^{-3} ; \% \mathrm{C}=1,3 ; \mathrm{Fe}=$ $162 \mathrm{mg} \cdot \mathrm{dm}^{-3} ; \mathrm{Cu}=0,8 \mathrm{mg} \cdot \mathrm{dm}^{-3} ; \mathrm{Zn}=66,0$ mg.dm ${ }^{-3}$ e $\mathrm{Mn}=11,5 \mathrm{mg} \cdot \mathrm{dm}^{-3}$. Foi realizada uma calagem com $700 \mathrm{~kg} \cdot \mathrm{ha}^{-1}$ de calcário dolomítico, aplicando-se metade do corretivo antes da aração e metade antes da gradagem, conforme recomendação de aplicação do Manual de Adubação do Estado do Rio de Janeiro (De Polli \& Almeida, 1988).

As mudas de mandioquinha-salsa, var. Amarela de Carandaí, normalmente cultivada na região, foram provenientes do mesmo local do experimento. Os rebentos para a formação das mudas foram selecionados de touceiras adultas que já haviam terminado o ciclo vegetativo, de onde foram destacados e cortados em bisel, padronizando-se assim o tamanho das mudas. Estas foram plantadas em canteiros de préenraizamento, onde permaneceram até os 60 dias e então levadas para o local do experimento e plantadas no local definitivo. Neste período foi mantida a umidade do solo (aproximadamente $3 / 4$ da capacidade de campo) sem qualquer aplicação de defensivo agrícola ou fertilizante químico.

As doses de N $\left(0 ; 60\right.$ e 120 kg.ha' $\left.a^{-1}\right)$, $\mathrm{P}_{2} \mathrm{O}_{5}\left(0 ; 150\right.$ e $\left.300 \mathrm{~kg} \cdot \mathrm{ha}^{-1}\right)$ e $\mathrm{K}_{2} \mathrm{O}(0 ; 80$ e $\left.160 \mathrm{~kg} \mathrm{ha}^{-1}\right)$, usando como fontes uréia, superfosfato simples e cloreto de potássio, foram acompanhadas de $15 \mathrm{~kg} \cdot \mathrm{ha}^{-1}$ de bórax (10\% de B), $5 \mathrm{~kg}$.ha ${ }^{-1}$ de sulfa-

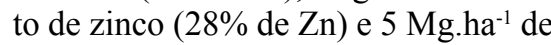
esterco de curral curtido. Os fertilizantes, assim como o esterco, foram distribuídos nas leiras e incorporados manualmente ao solo na profundidade de $0-10$ $\mathrm{cm}$. A adubação nitrogenada foi parcelada, sendo metade aplicada no plantio das mudas e outra metade, em cobertura 60 dias após o plantio. Utilizou-se de sistema de irrigação por aspersão, onde se irrigou sempre que necessário, a fim de manter a umidade do solo próxima da capacidade de campo.

O delineamento experimental foi de blocos ao acaso com quatro repetições e 27 tratamentos (fatorial $3 \times 3 \times 3$ ), com parcelas de 2,8 8 4,0 $\mathrm{m} \mathrm{e} 40$ plantas por parcela com espaçamento de $0,7 \times 0,4 \mathrm{~m}$. Foram descartadas as linhas externas de plantas (efeito bordadura), permanecendo 18 plantas na área útil de cada parcela. Efetuou-se quatro capinas manuais e adicionou-se uma cobertura morta (palhada de capim) para auxiliar no controle de plantas invasoras e a manutenção da umidade.

Foram realizadas quatro coletas de material vegetal durante o ciclo $(90 ; 150$; 210 e 300 dias após o transplante), amostrando-se quatro plantas por parcela e separando-se em planta inteira, parte aérea, propágulo (coroa e rebentos) e raízes, nas quais avaliou-se o acúmulo de massa seca. Na última coleta avaliouse a produtividade de raízes comercializáveis, considerando-se raízes comercializáveis aquelas cujo tamanho era maior ou igual a $8 \mathrm{~cm}$ de comprimento e diâmetro médio maior ou igual a 3 $\mathrm{cm}$. A avaliação dos dados foi efetuada pelo teste $\mathrm{F}$ de Fisher e procedeu-se à comparação das médias pelo teste Duncan. Quando os dados não se acharam em homocedasticia (teste Cochran \& Bartellet), foram transformados em $\log$ $\mathrm{x}$. As análises foram realizadas com o auxílio do programa estatístico Saeg.

\section{RESULTADOS E DISCUSSÃO}

O maior acúmulo de matéria seca na parte aérea ocorreu aos 180 dias após o plantio das mudas, com um decréscimo sucessivo até a colheita, o que indica o início da senescência da planta (Figura 1). O propágulo e as raízes apresentaram um crescimento vigoroso após a segunda coleta (150 dias), mostrando um grande acúmulo de reservas nestes dois órgãos da planta, conforme já mencionado por outros autores (Lima et al., 1985; Mesquita Filho \& Souza, 1996; Ortiz et al., 1998). Quanto aos órgãos raízes e propágulos, estes são responsáveis pela nova brotação da planta no seu segundo ciclo vegetativo (bianual) e servem como órgãos de reserva e propagação vegetativa, respectivamente. Houve grande translocação de fotoassimilados das folhas (fonte) para o propágulo e raízes (drenos) e aparentemente não foi influenciada pelo início da senescência da parte aérea aos 180 dias de transplantio, havendo um acúmulo crescente nestes órgãos de reserva até o final do ciclo (300 dias). Também se observou que as raízes atuaram como drenos preferenciais dos fotoassimilados, com o maior acúmulo aos 300 dias.

O clima tropical de altitude, particular à região serrana do Rio de Janeiro, semelhante à região Andina onde a espécie se originou, associado a práticas culturais mais recentes como o préenraizamento, a cobertura morta e a irrigação, juntamente com suprimento adequado de nutrientes, oferecem condições para se obter colheita mais precoce (menor que 12 meses de ciclo), com bons índices de produtividade. Isso permite para o produtor uma maior flexibilidade 
Tabela 1. Médias de produção de raízes comercializáveis $\left(\mathrm{kg} \cdot \mathrm{ha}^{-1}\right)$ em função das doses de nitrogênio, fósforo e potássio aplicadas, a um Nitossolo. Nova Friburgo, UFRRJ, 2000.

\begin{tabular}{|c|c|c|c|c|c|}
\hline \multirow{2}{*}{\multicolumn{2}{|c|}{ Nutrientes }} & \multicolumn{3}{|c|}{ Nitrogênio (kg.ha-1) } & \multirow{3}{*}{$\begin{array}{c}\text { Médias } \\
11701\end{array}$} \\
\hline & & 0 & 60 & 120 & \\
\hline \multirow{3}{*}{$\begin{array}{l}\text { Fósforo } \\
\left(\mathrm{kg} \cdot \mathrm{ha}^{-1} \mathrm{P}_{2} \mathrm{O}_{5}\right)\end{array}$} & 0 & 13043 & 12894 & 9167 & \\
\hline & 150 & 13668 & 13366 & 11778 & 12938 \\
\hline & 300 & 10930 & 13861 & 9606 & 11466 \\
\hline \multirow{3}{*}{$\begin{array}{l}\text { Potássio } \\
\left(\mathrm{kg} \cdot \mathrm{ha}^{-1} \mathrm{~K}_{2} \mathrm{O}\right)\end{array}$} & 0 & 10416 & 13455 & 9546 & 11139 \\
\hline & 80 & 15029 & 13735 & 9386 & 12718 \\
\hline & 160 & 12194 & 12932 & 11615 & 12247 \\
\hline Médias ${ }^{1 /}$ & & $12547 \mathrm{AB}$ & $13374 \mathrm{~A}$ & $10184 \mathrm{~B}$ & \\
\hline
\end{tabular}

${ }^{1 /}$ Médias seguidas de mesma letra não diferem entre si a 1\% pelo teste de Duncan. $\mathrm{CV}=35,94 \%$

na época de colheita e comercialização, aumentando assim a oferta da mandioquinha no mercado regional com melhor distribuição do produto durante o ano. Desta maneira pode-se diminuir a escassez do produto na entressafra e evitar a grande oscilação do preço desta olerícola no mercado do Rio de Janeiro.

Foi observada correlação positiva e significativa $(r=0,45 ; p=0,01)$ entre a massa fresca da parte aérea e produção de raízes comercializáveis, confirmando os resultados de Câmara et al. (1985). Contudo afirmações de que tratamentos na cultura que melhorem o desenvolvimento da parte aérea possam, consequentemente, melhorar a produção de raízes, ainda é assunto de investigação e mais pesquisa. Tem como fato, a afirmação de alguns produtores de que mudas maiores resultam em coroas maiores e parte aérea exuberante, mas nem sempre isto é acompanhado de maior produção de raízes.

Na colheita, realizada aos 300 dias, não foi observada resposta significativa às doses de fósforo e potássio sobre a produtividade de raízes comercializáveis. Apesar de se observar uma tendência quadrática nas respostas de fósforo e potássio, a disponibilidade destes nutrientes no solo, somado à adição de matéria orgânica, podem ter mascarado uma melhor diferenciação das respostas destes nutrientes. Contudo seria recomendável aplicar uma dose intermediária de $\mathrm{P}_{2} \mathrm{O}_{5}\left(150 \mathrm{~kg}\right.$.ha-1 $\left.{ }^{-1}\right)$ já que esta proporcionou produtividade $10 \%$ maior que a da testemunha, o que poderia ser vantajoso pelo alto valor comercial que alcançam as raízes no mercado. Para a aplicação de nitrogênio foi observada resposta significativa sendo a dose de $60 \mathrm{~kg} \mathrm{~N} . \mathrm{ha}^{-1}$ superior à dose de $120 \mathrm{~kg} \mathrm{~N} \cdot \mathrm{ha}^{-1}$, mas não diferindo da testemunha (Tabela 1). Mes- quita Filho et al. (1996) observaram efeito quadrático de $\mathrm{P}_{2} \mathrm{O}_{5}$ na produção de raízes comerciais e nenhuma resposta à adubação nitrogenada no cerrado em Latossolo com semelhantes características químicas ao Nitossolo utilizado neste experimento. No entanto, a diferença nas respostas se devem provavelmente ao tipo de argila no solo de cerrado que sendo de baixa atividade favorece a observação de carências nutricionais de fósforo e à diferença dos teores de matéria orgânica entre os solos no qual influenciam na disponibilidade de nitrogênio. Del Valle Junior et al. (1995) recomendam a aplicação de $\mathrm{N}$ para a produção de mandioquinha-salsa, sem comentarem o teor de matéria orgânica encontrado no solo e a disponibilidade de nitrogênio e de outros nutrientes para a planta no solo estudado.

O manejo da matéria orgânica na cultura parece ser de fundamental importância para se alcançar boa produtividade, indicando o seu potencial para cultivo em sistema orgânico de produção.

A produtividade deve ter sido influenciada pela adição de matéria orgânica, que disponibilizando nutrientes ao longo do ciclo da cultura, contribuiu para que não se observassem diferenças significativas referentes às aplicações de fósforo e potássio e para não se ter conseguido uma resposta definida às doses de nitrogênio aplicadas.

\section{AGRADECIMENTOS}

Agradecemos aos colegas de graduação de Agronomia pela ajuda nos trabalhos de campo e laboratório, ao Departamento de Solos da UFRRJ pelas dependências e equipamentos utilizados e a FAPERJ pelo apoio financeiro e bolsa de estudos.

\section{LITERATURA CITADA}

CÂMARA， F.L..A.; CASALI, V.W.D.; THIÉBAUT, J.T.L.; MEDINA, P.V.L. Época de plantio, ciclo e amassamento dos pecíolos da mandioquinha-salsa. Horticultura Brasileira, Brasília, v. 3, n. 2, p. 25-28, 1985.

DEL VALLE JUNIOR, R.; ORTIZ, C.E.; SANTIAGO-CORDOVA, M.A. Fertilization of arracacha in na Ultisol. Rio Pedras, v. 79, n. 3-4, p. 183-185, 1995. Research Note.

DE-POLLI, H.; ALMEIDA, D.L. Manual de adubação para o Estado do Rio de Janeiro. Rio de Janeiro: UFRRJ, 1988. 179 p.

LIMA, L.A.; ZANIN, A.C.W.; MISCHAN, M.M. Acúmulo de matéria seca e de nutrientes por plantas de mandioquinha-salsa colhida dos nove aos doze meses de plantio. In: CONGRESO BRASILEIRO DE OLERICULTURA, 25., 1985 , Blumenau. Resumos...: Brasília, Horticultura Brasileira, Brasília, 1985. p. 76.

MESQUITA FILHO, M.V.; SOUZA, A.F. Acúmulo de matéria seca e de nutrientes na cultura de mandioquinha-salsa em solo de cerrado. In: REUNIÃO BRASILEIRA DE FERTILIDADE DE SOLO E NUTRIÇÃO DE PLANTAS, 22., 1996, Manaus. Resumos... Manaus: SBCS, 1996.p. 431-432. MESQUITA FILHO M.V.; SOUZA, A.F.; SILVA, H.R.; SANTOS, F.F.; OLIVEIRA, S.A. Adubação nitrogenada e fosfatada para a produção comercializável de mandioquinha-salsa em Latossolo vermelho-amarelo. Horticultura Brasileira, Brasília, v. 14, n. 2, p. 211-215, 1996.

ORTIZ, C.A.; ORENGO-SANTIAGO, E.; ACÍN, N.M. Dry weight accumulation and nutrient uptake by arracacha grown under controlled conditions. San Juan: University of Puerto Rico, 1998. 9 p.

REGHIN, M.Y.; OTTO, R.F.; SILVA, J.B.C. "Stimulate Mo" e proteção com tecido não tecido no pré-enraizamento de mudas de mandioquinhasalsa. Horticultura Brasileira, Brasília, v. 18, n. 1, p. 53-56, 2000.

SILVA, L.R.; BLANCO, H.G.; NORMANHA, E.S. FREIRE, E.S. Efeitos de doses crescentes de nitrogênio, fósforo e potássio sobre a produção de mandioquinha-salsa. Bragantia, Campinas, v. 25, n. 33, p. 365-369, 1966.

SILVA, H.R.; SANTOS, F.F. Irrigação. In: SANTOS, F.F.; CARMO, C.A.S. ed. Mandioquimha-salsa Manejo cultural. Brasília: Embrapa, 1998. p. 37-43.

VIEIRA, M.C. Avaliação do crescimento e da produção de clones e efeito de resíduo orgânico e de fósforo em mandioquinha-salsa no Estado de Mato grosso do Sul. Viçosa: UFV, 1995. 146 p. (Tese doutorado) 